\title{
An OLG model of growth with longevity: when grandparents take care of grandchildren
}

\author{
Luciano Fanti · Luca Gori
}

Received: 27 October 2011 / Accepted: 16 February 2014 / Published online: 29 March 2014

(C) ISEG 2014

\begin{abstract}
By assuming that grandparents take care of grandchildren, this paper aims at studying the effects of longevity on long-term economic growth in a model with overlapping generations and endogenous fertility. We show that an increase in longevity may: (i) reduce the long-term economic growth; (ii) increase the supply of labour, and (iii) cause fertility either to increase of decrease depending on the size of time spent by grandparents to rise grandchildren. These findings also hold in an endogenous growth setting à la Romer (J Polit Econ 94:1002-1037, 1986).
\end{abstract}

Keywords Longevity - OLG model

JEL Classifications $\mathrm{J} 13 \cdot \mathrm{J} 22 \cdot \mathrm{O} 41$

\footnotetext{
L. Fanti

Department of Economics and Management, University of Pisa, Via Cosimo Ridolfi 10, 56124

Pisa PI, Italy

e-mail: 1fanti@ec.unipi.it; fanti.luciano@gmail.com

L. Gori

Department of Law, University of Genoa, Via Balbi, 30/19, 16126 Genoa GE, Italy

e-mail: luca.gori@unige.it; dr.luca.gori@gmail.com
} 